\title{
Prevalence and spectrum of BRCA germline variants in mainland Chinese familial breast and ovarian cancer patients
}

\author{
Yeong C. Kim ${ }^{1, *}$, Linli Zhao ${ }^{1, *}$, Hanwen Zhang ${ }^{1, *}$, Ye Huang ${ }^{1}$, Jian Cui ${ }^{1}$, Fengxia \\ Xiao', Bradley Downs ${ }^{1}$ and San Ming Wang ${ }^{1}$ \\ ${ }^{1}$ Department of Genetics, Cell Biology and Anatomy, College of Medicine, University of Nebraska Medical Center, Omaha, \\ NE, USA \\ * These authors have contributed equally to the study \\ Correspondence to: San Ming Wang, email: sanming.wang@unmc.edu \\ Keywords: germline variant, BRCA1, BRCA2, mainland Chinese, familial breast and ovarian cancer \\ Received: September 28, 2015 Accepted: January 18,2016 Published: February 02, 2016
}

\section{ABSTRACT}

Germline mutations in BRCA1 and BRCA2 are the most penetrating genetic predispositions for breast and ovarian cancer, and their presence is largely ethnicspecific. Comprehensive information about the prevalence and spectrum of BRCA mutations has been collected in European and North American populations. However, similar information is lacking in other populations, including the mainland Chinese population despite its large size of 1.4 billion accounting for one fifth of the world's population. Herein, we performed an extensive literature analysis to collect BRCA variants identified from mainland Chinese familial breast and ovarian cancer patients. We observed 137 distinct BRCA1 variants in 409 of 3,844 and 80 distinct BRCA2 variants in 157 of 3,024 mainland Chinese patients, with an estimated prevalence of $10.6 \%$ for BRCA1 and $5.2 \%$ for BRCA2. Of these variants, only $40.3 \%$ in BRCA1 and $42.5 \%$ in $B R C A 2$ are listed in current Breast Cancer Information Core database. We observed higher frequent variation in BRCA1 exons 11A, 11C, 11D, and 24 and $B R C A 2$ exon 10 in Chinese patients than in the patients of other populations. The most common pathogenic variant in BRCA1 was C.981_982delAT in exon 11A, and in BRCA2 C.3195_3198delTAAT in exon 11B and C.5576_5579delTTAA in exon 11E; the most common novel variant in BRCA1 was C.919A>G in exon 10A, and in BRCA2 c.7142delC in exon 14. None of the variants overlap with the founder mutations in other populations. Our analysis indicates that the prevalence of BRCA variation in mainland Chinese familial breast and ovarian cancer patients is at a level similar to but the spectrum is substantially different from the ones of other populations.

\section{INTRODUCTION}

$B R C A 1$ and $B R C A 2(B R C A)$ are rapidly evolving genes with high levels of variation across primate species [1-3]. Germline mutations in BRCA predispose individuals for breast and ovarian cancer [4-5]. Extensive efforts have been made to determine the prevalence and spectrum of germline mutations in both genes to aid clinical diagnosis of and prevent the disease [6-8].

Increasing evidence indicates that the presence of $B R C A$ germline mutations in human familial breast and ovarian cancer is largely ethnic-specific [9]. For example, 185delAG [c.66_67delAG according to human genome variation society (HGVS) nomenclature] and
5382insC (c.5263_5264insC) in BRCA1 and 6174delT (c.5946delT) in BRCA2 are highly prevalent in Ashkenazi Jews [10]; c.4153delA (c.4035delA), C61G (c. $-58 \mathrm{C}>\mathrm{G})$, and 5382insC (c.5263 5264insC) in BRCA1 are common in Polish familial breast cancer patients [11]; c.303T $>\mathrm{G}$, c. $5324 \mathrm{~T}>\mathrm{G}$, c.1623dupG, and c.4122 4123delTG in $B R C A 1$ are frequently present in the familial breast cancer patients of African ancestry [12]; ex9-12del in BRCA1 is often seen in Mexican familial breast and ovarian cancer patients [13], and c. $7480 \mathrm{C}>\mathrm{T}$ in $B R C A 2$ is enriched in Korean familial breast cancer patients [14].

$B R C A$ mutations have been extensively analyzed in European and North American populations, but much less are known about them in Asian, African, and Latin American populations, although these contribute most of 
the total human population. Using the data from Western populations to interpret $B R C A$ mutations in non-Western patients can be inaccurate and lead to misdiagnoses. Therefore, knowledge of ethnic-specific $B R C A$ mutations is urgently demanding and will be highly beneficial for the patients.

Mainland China has a population size of nearly 1.4 billion, accounting for one fifth of the human population worldwide. However, limited information about $B R C A$ mutations in this large population is available in current $B R C A$ variation databases. For example, only 13 of the 1,791 BRCA1 variants and three of the 2,000 BRCA2 variants in the Breast Cancer Information Core (BIC) database were derived exclusively from mainland Chinese patients [15]. We hypothesized that 1) $B R C A$ variation may be common in this population, and 2) many variants representing potential mutations may have already been identified but this information is unknown outside the Chinese scientific community, because many Chinese scientists publish in Chinese rather than in English and most Chinese medical and health science journals are not included in international journal databases [16]. To test our hypothesis, we performed an extensive survey of Chinese and English scientific literature to collect $B R C A$ variant data derived solely from mainland Chinese familial breast and ovarian cancer patients (Figure 1).

\section{RESULTS AND DISCUSSION}

\section{Identification of publications}

We identified 32 Chinese publications, including 24 peer-reviewed papers and eight graduate theses (Supplementary Table 1), and 11 peer-reviewed English papers. This totaled 43 publications covering between 2003 and 2015 reported $B R C A$ variants from mainland Chinese familial breast and ovarian cancer patients [1759].

From these publications, we identified familial breast cancer cases using the inclusion criteria described in each publication: at least one first-degree relative with breast cancer irrespective of age; breast cancer diagnosed before the age of 35 years with a family history of breast and/or ovarian cancer; at least one or two first- or seconddegree relatives diagnosed with breast cancer at any age; at least three relatives affected by breast cancer or

\section{Search in Chinese databases for Chinese publications reporting $B R C A 1$ and $B R C A 2$ mutations in mainland Chinese patients}

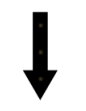

Publications in Chinese identified

\section{Search in Pubmed for English publications reporting $B R C A 1$ and $B R C A 2$ mutations in mainland Chinese patients}

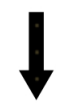

Publications in Englsih identified

\section{$\downarrow$}

$B R C A 1$ and $B R C A 2$ distinct mutations identified in Chinese familial breast cancer and ovarian cancer cases

$\downarrow$

Compare with BIC database

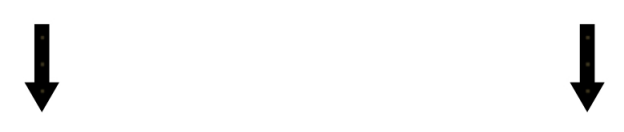

BIC-matched BRCA1 and BRCA2 mutations BIC-not matched BRCA1 and BRCA2 mutations

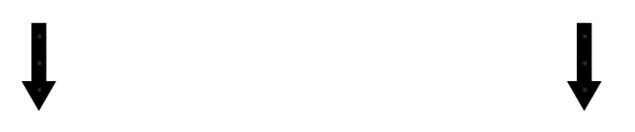

\section{Classify matched mutations}

Annotate no-matched mutations

Figure 1: Outline of the study. It shows the steps taken to extract information about $B R C A$ variation in mainland Chinese familial breast and ovarian cancer patients. 
breast and ovarian cancer; triple-negative breast cancer patients diagnosed before the age of 45 years; bilateral breast cancer diagnosed before the age of 50 years; one or more primary breast/ovarian cancers in first- or seconddegree relatives; and at least one relative with cancer other than breast and ovarian cancer that is known to be BRCA1-related. From these publications, we also collected pedigree and genotype information available from family members although most publications only analyzed the proband without such information (Supplementary Table 2).

We identified a total of 3,844 familial breast and ovarian cancer cases from the original studies. All of these were analyzed for $B R C A 1$ (3,129 covered all exons), and 3,024 were analyzed for $B R C A 2$ (2,854 covered all exons); $92 \%$ of the 3,844 cases were Han Chinese and the rest were from other ethnic groups (Hui, Mongol, Uyghur, Kazakh, and Russian) (Table 1). These studies were performed in 15 provinces or cities in mainland China, mostly in the densely populated, economically advanced eastern coast area, with the exception of Xinjiang and
Ningxia regions (Figure 2). The information highlights the need to analyze the population in so far uncovered regions to fully determine the prevalence and spectrum of $B R C A$ mutations in the entire mainland Chinese population.

Multiple assays including hetero-duplex formation, single-strand conformation polymorphism (SSCP), denaturing high-performance liquid chromatography (DHPLC), and Sanger sequencing were used in the original studies. All BRCA1 and BRCA2 variants collected in our current study were identified by either direct Sanger sequencing or by Sanger sequencing validation for the results from other assays (Table 1).

\section{$B R C A$ variants identified from publications}

By mining the variant data from the 3,844 cases, we identified a total of 137 distinct $B R C A 1$ variants in 409 cases, and 80 distinct $B R C A 2$ variants in 157 cases (Table 2, Supplementary Table 3; Table 3, Supplementary Table 4). Of the 137 BRCAl variants, 33 (24.6\%) were detected

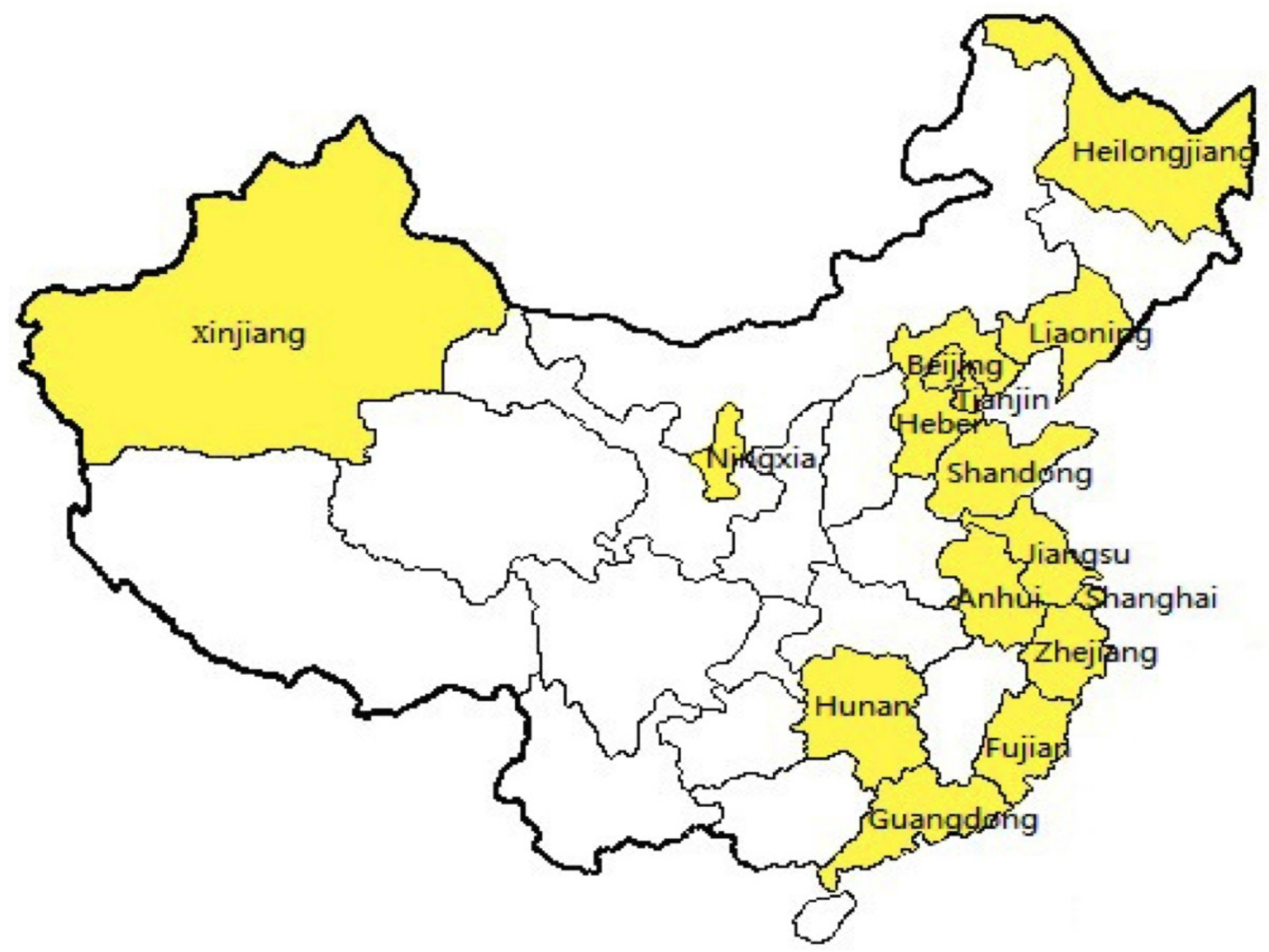

Figure 2: Geographic locations of the original studies. The original studies were performed in 15 provinces and cities in mainland China. Of these, 13 were in east coast area of Han Chinese and two were in Xinjiang and Ningxia of other ethnic groups. 
Table 1: Publications reporting BRCA mutations in mainland Chinese patients

\begin{tabular}{|c|c|c|c|c|c|c|c|c|c|}
\hline \multirow{2}{*}{ Year } & \multirow[t]{2}{*}{ Location } & \multirow[t]{2}{*}{ Ethnicity } & \multirow[t]{2}{*}{ Cases } & \multicolumn{2}{|l|}{ Targeted exons } & \multicolumn{2}{|c|}{ Published in } & \multirow[t]{2}{*}{ Methods* } & \multirow[t]{2}{*}{ Reference } \\
\hline & & & & BRCA1 & BRCA2 & Chinese & English & & \\
\hline 2003 & Beijing & Han & 9 & All & & + & & $\mathrm{a}$ & 17 \\
\hline 2003 & Beijing & Han & 26 & All & & & + & $\mathrm{a}$ & 18 \\
\hline 2003 & Jiangsu & Han & 23 & All but 1,4 & & + & & $\mathrm{a}$ & 19 \\
\hline 2003 & Shanghai & Han & 20 & All & & & + & $\mathrm{a}$ & 20 \\
\hline 2003 & Beijing & Han & 15 & $\begin{array}{l}4,8,11,18,19, \\
20\end{array}$ & $\begin{array}{l}\text { All but } 15 \\
16,25,26\end{array}$ & + & & $b$ & 21 \\
\hline 2004 & Shanghai & Han & 645 & All & All & & + & $\mathrm{b}$ & 22 \\
\hline 2005 & Shanghai & Han & 13 & All & All & + & & $\mathrm{a}$ & 23 \\
\hline 2005 & Anhui & Han & 76 & $\begin{array}{l}\text { All but 1,3,4, } \\
6,7,10,14,19 \text {, } \\
21-24\end{array}$ & & + & & $\mathrm{a}$ & 24 \\
\hline 2006 & Shanghai & Han & 35 & All & All & + & & $\mathrm{a}$ & 25 \\
\hline 2006 & Shanghai & Han & 33 & All & All & & + & $\mathrm{a}$ & 26 \\
\hline 2007 & Hebei & Han & 18 & $2,11 \mathrm{~A}, 11 \mathrm{~B}, 20$ & 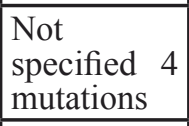 & + & & c & 27 \\
\hline 2007 & $\begin{array}{l}\text { Shanghai } \\
\text { Liaoning } \\
\text { Shadong }\end{array}$ & Han & 177 & $\begin{array}{l}\text { Not specified } 7 \\
\text { mutations }\end{array}$ & & + & & $\mathrm{a}$ & 28 \\
\hline 2007 & $\begin{array}{l}\text { Shanghai } \\
\text { Liaoning } \\
\text { Shadong }\end{array}$ & Han & 39 & All & & + & & $\mathrm{a}$ & 29 \\
\hline 2007 & $\begin{array}{l}\text { Shanghai } \\
\text { Liaoning } \\
\text { Shadong }\end{array}$ & Han & 60 & $\begin{array}{l}\text { 1100delAT, } \\
\text { IVS17-1G }>\text { T, } \\
\text { IVS21+1G }>\text { C, } \\
\text { 5640delA }\end{array}$ & & + & & $\mathrm{a}$ & 30 \\
\hline 2007 & $\begin{array}{l}\text { Shanghai } \\
\text { Liaoning } \\
\text { Shadong }\end{array}$ & Han & 139 & All & All & + & & $\mathrm{a}$ & 31 \\
\hline 2007 & Guangdong & Han & 17 & All & & + & & $\mathrm{a}$ & 32 \\
\hline 2008 & $\begin{array}{l}\text { Shanghai } \\
\text { Liaoning } \\
\text { Shandong }\end{array}$ & Han & 115 & All & All & + & & $\mathrm{a}$ & 33 \\
\hline 2008 & $\begin{array}{l}\text { Shanghai } \\
\text { Liaoning } \\
\text { Shadong }\end{array}$ & Han & 489 & All & All & & + & d & 34 \\
\hline 2008 & Shandong & Han & 25 & All & All & + & & $\mathrm{a}$ & 35 \\
\hline 2008 & $\begin{array}{l}\text { Shanghai } \\
\text { Guangdong } \\
\text { Liaoning }\end{array}$ & Han & 219 & All & All & + & & $\mathrm{a}$ & 36 \\
\hline 2009 & Shandong & Han & 25 & All & & + & & $\mathrm{a}$ & 37 \\
\hline 2009 & Beijing & Han & 139 & All & & & + & $\mathrm{a}$ & 38 \\
\hline 2009 & Hunan & Han & 26 & All & All & + & & $\mathrm{a}$ & 39 \\
\hline 2009 & Fujian & Han & 20 & 11 & & + & & $\mathrm{b}$ & 40 \\
\hline 2009 & Tianjin & Han & 5 & $1,11,16,20$ & & + & & $\mathrm{a}$ & 41 \\
\hline 2009 & Shandong & Han & 30 & 2,20 & & + & & $\mathrm{a}$ & 42 \\
\hline 2010 & Heilongjiang & Han & 54 & All but 1,4 & & + & & $\mathrm{c}$ & 43 \\
\hline 2011 & Shandong & Han & 8 & 2,11 & & + & & $\mathrm{b}$ & 44 \\
\hline
\end{tabular}




\begin{tabular}{|c|c|c|c|c|c|c|c|c|c|}
\hline 2012 & Hebei & Han & 13 & $2,11,20$ & 11 & + & & $\mathrm{c}$ & 45 \\
\hline 2012 & Hebei & Han & 64 & All & All & + & & $\mathrm{a}$ & 46 \\
\hline 2012 & Ningxia & Hui & 7 & $5,11,18,20,24$ & 10,11 & + & & $b$ & 47 \\
\hline 2012 & Guangdong & Han & 92 & All but 1,4 & & + & & $\mathrm{b}$ & 48 \\
\hline 2012 & Beijing & Han & 409 & All & All & & + & $\mathrm{b}$ & 49 \\
\hline 2012 & Zhejiang & Han & 92 & $\begin{array}{l}3,8,11,12,13, \\
24\end{array}$ & $\begin{array}{l}3,5,6,10, \\
11,18,22, \\
23\end{array}$ & + & & $\mathrm{b}$ & 50 \\
\hline 2013 & Zhejiang & Han & 62 & All & All & + & & $\mathrm{b}$ & 51 \\
\hline 2013 & Xinjiang & Han & 30 & All & All & + & & $\mathrm{a}$ & 52 \\
\hline 2013 & Xinjiang & Han & 79 & All & All & & + & $\mathrm{a}$ & 53 \\
\hline 2014 & Xinjiang & $\begin{array}{l}\text { Han } \\
\text { Mongol } \\
\text { Hui Uygur }\end{array}$ & 214 & All & All & + & & $\mathrm{a}$ & 54 \\
\hline 2014 & Xinjiang & Han & 25 & Not specified & $\begin{array}{l}\text { Not } \\
\text { specified }\end{array}$ & & + & $\mathrm{a}$ & 55 \\
\hline 2014 & Shanghai & Han & 2 & All & All & + & & $\mathrm{e}$ & 56 \\
\hline 2015 & Xinjiang & $\begin{array}{l}\text { Han } \\
\text { Mongol } \\
\text { Hui Uygur } \\
\text { Kazakh } \\
\text { Russian }\end{array}$ & 82 & All & All & + & & $\mathrm{a}$ & 57 \\
\hline 2015 & Beijing & Han & 109 & All & All & & + & $\mathrm{b}$ & 58 \\
\hline 2015 & Shanghai & Han & 64 & All & All & & + & $\mathrm{e}$ & 59 \\
\hline Total & & & 3,844 & 3844 & 3024 & 32 & 11 & & 43 \\
\hline
\end{tabular}

*a. DHPLC, Sanger sequencing; b. Sanger sequencing; c. SSCP, Sanger sequencing; d. SSCP, DHPLC, Sanger sequencing; e. NGS, Sanger sequencing

by at least two different studies; of the $80 B R C A 2$ variants, $22(27.2 \%)$ were detected by at least two different studies.

\section{Prevalence assessment}

The prevalence of the variant carriers was $10.6 \%$ $(409 / 3,844)$ for $B R C A 1$ and $5.2 \%(157 / 3,024)$ for $B R C A 2$ (Of the 3,844 cases, all were used for $B R C A 1$, but 3,024 were used for $B R C A 2)$. The total number of cases used for all exon analysis was 3,129 in BRCA1 and 2,854 in $B R C A 2$. Thus, the total number of cases in the $B R C A 2$ group accounted for $91.2 \%$ of the BRCA1 $(2,854 / 3,129)$. Therefore, the different prevalence of $B R C A 1$ and $B R C A 2$ variations is unlikely caused by the analysis of different cases in each group but instead reflects the fact that $B R C A 1$ has a higher prevalence than $B R C A 2$ in Chinese population. This pattern differs from that in the neighboring Korean population, which has a much higher prevalence of $B R C A 2$ variation than $B R C A 1$ variation [14]. The variation types included frameshift, nonsense, missense, and splicing changes. Majority of the variants except a few do not have frequency information in genome

databases, indicating that the variants are mostly rare in human population (Supplementary Table 3, Supplementary Table 4).

\section{Exon distribution of $B R C A$ variants between Chinese and other patient populations}

We compared exon distribution frequencies of $B R C A$ variations between mainland Chinese patients and other patient populations represented in the BIC database. We compared the ratios calculated as: number of variation cases in each exon / total number of variation cases in each data set. The total number of variation cases (entries) in the BIC dataset was 15,311 for BRCA1 [61] and 14,914 for $B R C A 2$ [62]; the total number of variation cases in this study was 409 for BRCA1 and 157 for BRCA2. The results showed that the distribution frequencies in 13 out of 24 BRCA1 exons were significantly different between between mainland Chinese and BIC populations (Figure $3 \mathrm{~A})$. Variants in mainland Chinese were particularly lower in exons 2 and 20 but higher in exons $11 \mathrm{~A}, 11 \mathrm{C}$, and 11D (exon 11 is arbitrarily divided into $11 \mathrm{~A}, 11 \mathrm{~B}, 11 \mathrm{C}$, and 


\section{A. BRCA1}

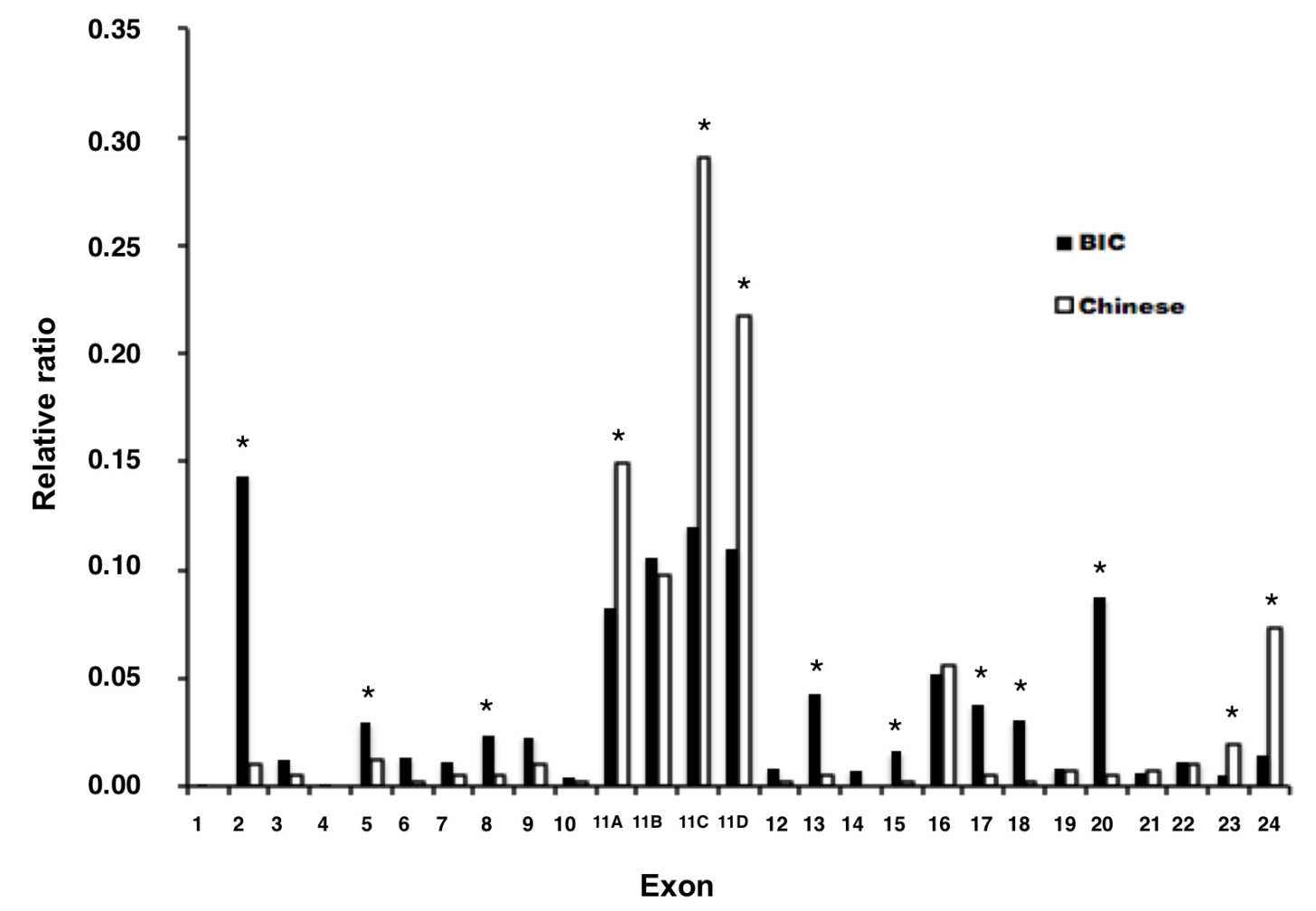

\section{B. BRCA2}

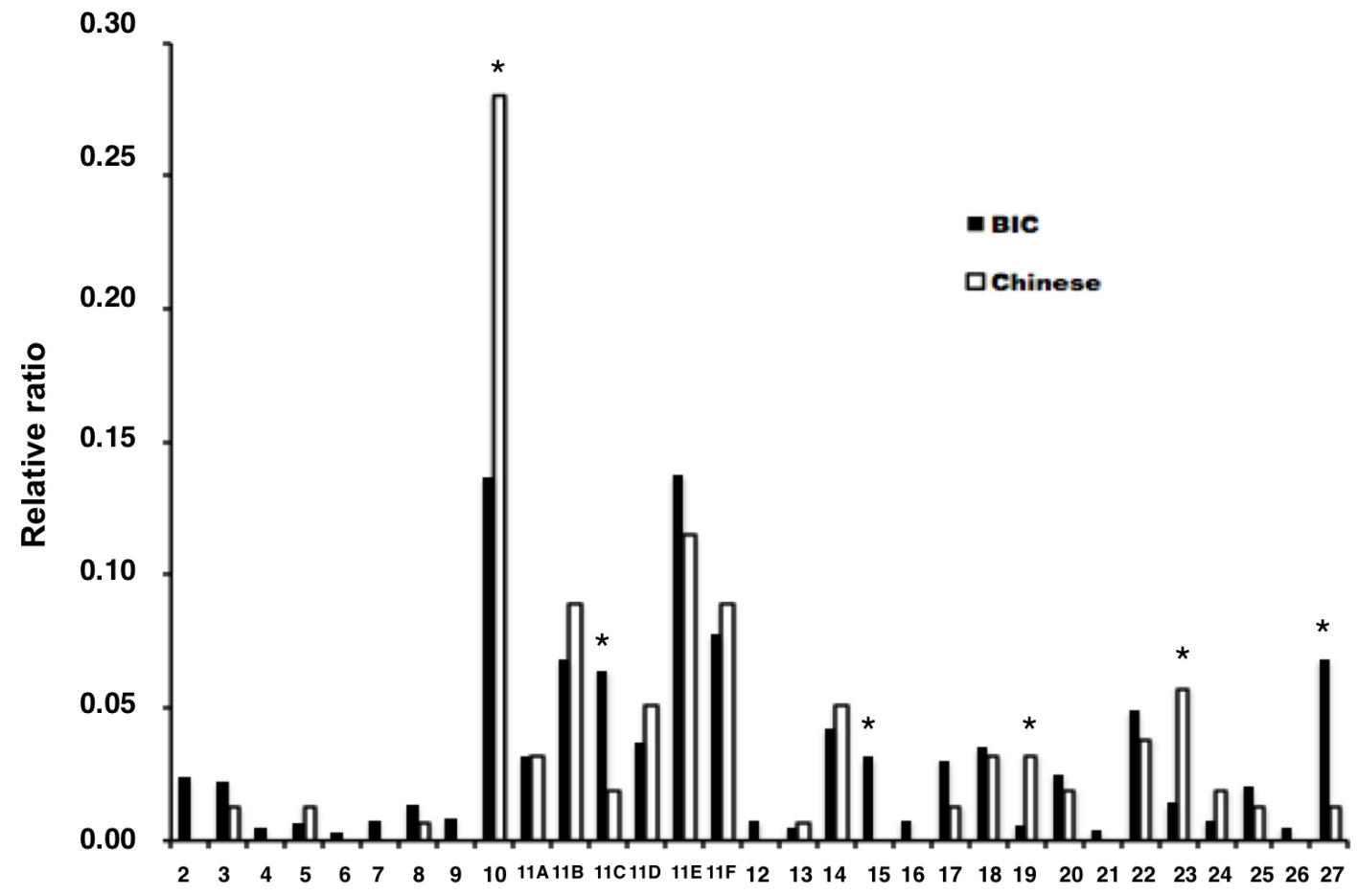

Figure 3: Comparison of exon distribution frequencies of $B R C A$ variation between mainland Chinese and BIC populations. Relative ratios between these two datasets were used for the comparison (see text for the details). Chi square $\left(\chi^{2}\right)$ and Fisher exact test were used for statistics analysis. "**" refers to $p<0.05$ (actual P values listed in Supplementary Table 5). A. Variant distribution in BRCA1. B. Variant distribution in BRCA2. 
$11 \mathrm{D}$ by the BIC database because of its large size) and exon 24 than in other populations. The variants in BRCA1 exons 11A, 11C, 11D and exon 24 occurred in 299 of the 409 (73.1\%) Chinese BRCA1- variation cases. In $B R C A 2$, the differences were smaller with only 6 out of 27 exons showed significant difference between mainland Chinese and BIC populations. Exon 10 was the highest in mainland Chinese with 44 of the 157 (28\%) Chinese BRCA2variation cases (Figure 3B). Therefore, BRCA1 exon 11A, $11 \mathrm{C}, 11 \mathrm{D}$, exon 24 , and $B R C A 2$ exon 10 are the variation hot spots in mainland Chinese patients.

\section{BIC-matched variants}

Fifty-six (40.3\%) BRCA1 and 34 (42.5\%) BRCA2 variants exist in the BIC database (Figure 4). Of these, 27 $B R C A 1$ and $23 B R C A 2$ variants are classified by $\mathrm{BIC}$ as Class 5 (Pathogenic), $27 B R C A 1$ and $9 B R C A 2$ variants as Pending [most were variants of unknown significance (VUS)], and two BRCA1 and two BRCA2 variants as Class 1 (Benign). The most common pathogenic BRCA1 variant was c.981_982delAT (p.Cys328*) in exon 11A ( $n$ $=18$ ), confirming the previous observation in a smaller group of patients [30]. The frequency of this variant was substantially higher in mainland Chinese than in non-

\section{Mutation in BIC Mutation in mainland Chinese}

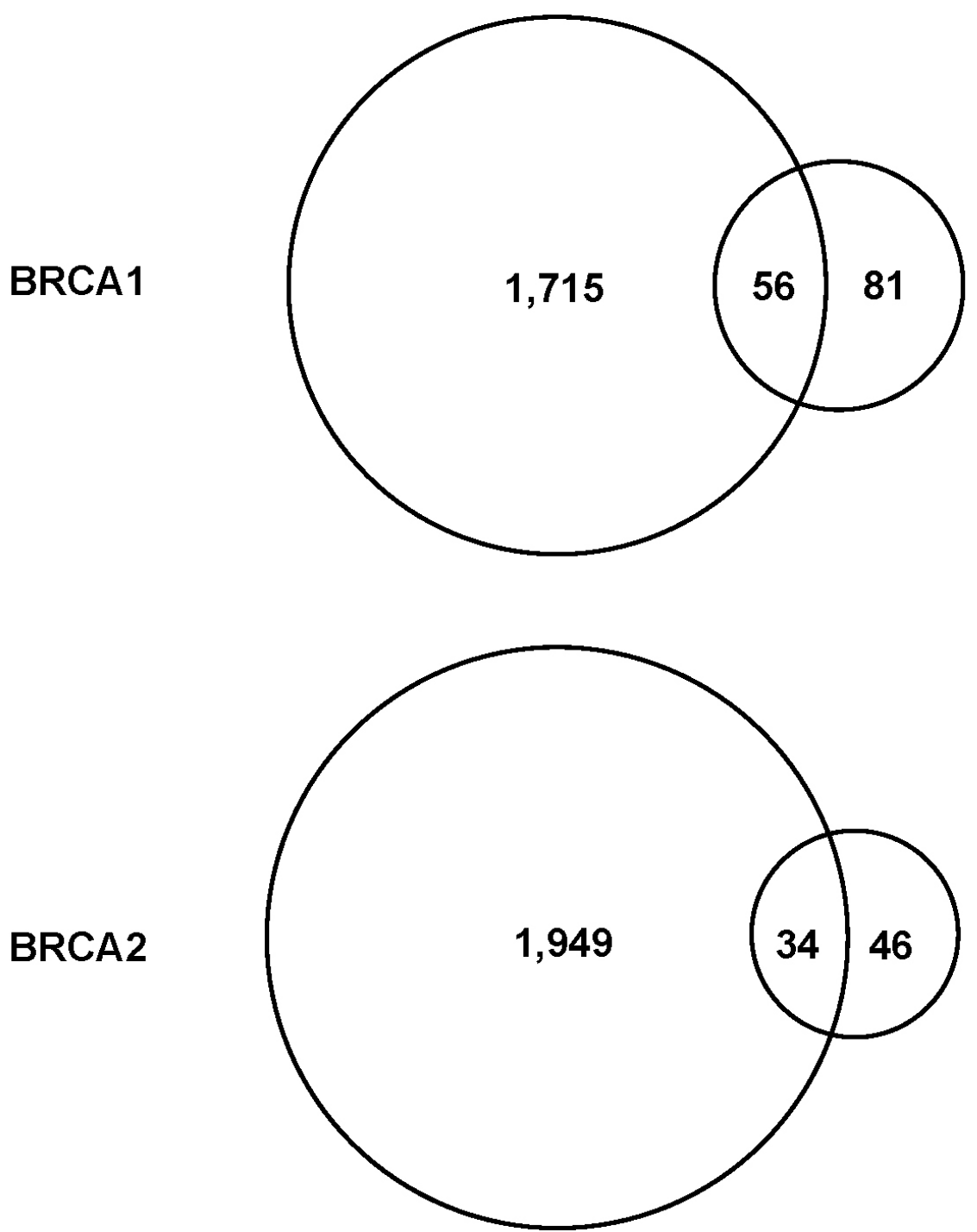

Figure 4: Matching $\boldsymbol{B R C A}$ variants to the BIC database. The $137 \mathrm{BRCA1}$ and $80 B R C A 2$ distinct variants from mainland Chinese patients were compared with the 1,781 $B R C A 1$ and 2,000 BRCA2 distinct variants in the BIC database. Of the Chinese variants, $56 B R C A 1$ and $34 B R C A 2$ variants were matched, whereas $82 B R C A 1$ and $46 B R C A 2$ variants were not. 
Table 2: Examples of $B R C A 1$ variants identified in mainland Chinese familial breast and ovarian cancer patients*

\begin{tabular}{|c|c|c|c|c|c|c|}
\hline Class (BIC) & Exon & HGVS annotation & & \begin{tabular}{|l} 
Variation type \\
\end{tabular} & Total case & Carrier \\
\hline & & cDNA & Protein & & & \\
\hline Class 5 & $11 \mathrm{~A}$ & c.981 982delAT & p.Cys328* & Frameshift & 1142 & 18 \\
\hline Class 5 & $11 \mathrm{~A}$ & c. $1116 \mathrm{G}>\mathrm{A}$ & p.Trp372* & Nonsense & 480 & 5 \\
\hline Class 5 & 11B & c. 2110 2111delAA & p.Asn704Cysfs*7 & Frameshift & 822 & 8 \\
\hline Class 5 & 11B & c. $2275 \mathrm{C}>\mathrm{T}$ & p.Gln759* & Nonsense & 473 & 5 \\
\hline Class 5 & $11 \mathrm{~B}$ & c.1556delA & p.Lys519Argfs*13 & Frameshift & 7 & 2 \\
\hline Class 5 & $11 \mathrm{~B}$ & c. $2138 \mathrm{C}>\mathrm{G}$ & p.Ser713* & Nonsense & 50 & 2 \\
\hline Class 5 & $11 \mathrm{D}$ & c.3531delT & p.Phe1177Leufs*33 & Frameshift & 7 & 6 \\
\hline Class 5 & $11 \mathrm{D}$ & c.3916_3917delTT & p.Leu1306Aspfs*23 & Frameshift & 518 & 3 \\
\hline Class 5 & $11 \mathrm{D}$ & c. $3640 \mathrm{G}>\mathrm{T}$ & p.Glu1214* & Nonsense & 239 & 3 \\
\hline Class 5 & $11 \mathrm{D}$ & c. $3607 \mathrm{C}>\mathrm{T}$ & p.Arg1203* & Nonsense & 239 & 2 \\
\hline Class 5 & $11 \mathrm{D}$ & c.4065_4068delTCAA & p.Asn1355Lysfs*10 & Frameshift & 171 & 2 \\
\hline Class 5 & 11D & c.3770_3771delAG & p.Glu1257Glyfs*9 & Frameshift & 548 & 2 \\
\hline Class 5 & 19 & c. $5154 \mathrm{G}>\mathrm{A}$ & p.Trp1718* & Nonsense & 62 & 2 \\
\hline Pending & $\mathrm{I}-5$ & c. $212+1 \mathrm{G}>\mathrm{T}$ & - & IVS & 214 & 3 \\
\hline Pending & $11 \mathrm{~A}$ & c. $1064 \mathrm{~A}>\mathrm{G}$ & p.Lys355Arg & Missense & 92 & 8 \\
\hline Pending & $11 \mathrm{~B}$ & c. $2077 \mathrm{G}>A$ & p.Asp693Asn & Missense & 214 & 3 \\
\hline Pending & 11B & c. $1934 \mathrm{C}>\mathrm{A}$ & p.Ser645Tyr & Missense & 214 & 2 \\
\hline Pending & $11 \mathrm{C}$ & c. $3113 \mathrm{~A}>\mathrm{G}$ & p.Glu1038Gly & Missense & 437 & 31 \\
\hline Pending & $11 \mathrm{C}$ & c. $3119 \mathrm{G}>\mathrm{A}$ & p.Ser1040Asn & Missense & 667 & 3 \\
\hline Pending & $11 \mathrm{D}$ & c. $3548 \mathrm{~A}>\mathrm{G}$ & p.Lys1183Arg & Missense & 439 & 34 \\
\hline Pending & $11 \mathrm{D}$ & c. $3508 \mathrm{~A}>\mathrm{T}$ & p.Ile1170Phe & Missense & 76 & 2 \\
\hline Pending & $\mathrm{I}-16$ & c. $4986+1 \mathrm{G}>\mathrm{A}$ & - & IVS & 101 & 2 \\
\hline Pending & 16 & c. $4837 \mathrm{~A}>\mathrm{G}$ & p.Ser1613Gly & Missense & 302 & 17 \\
\hline Pending & 22 & c. $.5363 \mathrm{G}>\mathrm{T}$ & p.Gly1788Val & Missense & 548 & 2 \\
\hline Pending & 24 & c.5470_5477delATTGGGCA & p.Ile1824Aspfs*3 & Frameshift & 1505 & 20 \\
\hline Pending & 24 & c.5521 delA & p.Ser1841Valfs*2 & Frameshift & 1272 & 8 \\
\hline Pending & 24 & c. $.5503 \mathrm{C}>\mathrm{T}$ & p.Arg1835* & Nonsense & 173 & 2 \\
\hline Novel & 2 & c. $-1 \mathrm{~A}>\mathrm{T}$ & - & IVS & 76 & 2 \\
\hline Novel & $11 \mathrm{~A}$ & c. $919 A>G$ & p.Lys307Glu & Missense & 92 & 10 \\
\hline Novel & $11 \mathrm{~A}$ & c. $1660 \mathrm{G}>\mathrm{T}$ & p.Glu554* & Nonsense & 628 & 3 \\
\hline Novel & $11 \mathrm{~B}$ & c. 2073 delA & p.Arg691Serfs*10 & Frameshift & 430 & 5 \\
\hline Novel & $11 \mathrm{~B}$ & c.2248_2252delCTCAT & p.Leu750Valfs*10 & Frameshift & 518 & 2 \\
\hline Novel & $11 \mathrm{C}$ & c. $2572 \mathrm{C}>\mathrm{T}$ & p.Gln $858^{*}$ & Nonsense & 782 & 4 \\
\hline Novel & $11 \mathrm{C}$ & c. $3122 \mathrm{C}>\mathrm{G}$ & p.Ser1041* & Nonsense & 743 & 4 \\
\hline Novel & $11 \mathrm{C}$ & c.2798_2799delGT & p.Gly933Alafs*4 & Missense & 743 & 3 \\
\hline Novel & $11 \mathrm{C}$ & c.3294delT & p.Pro1099Leufs*10 & Frameshift & 239 & 3 \\
\hline Novel & $11 \mathrm{C}$ & c.2939T $>A$ & p.Ile980Lys & Missense & 214 & 2 \\
\hline Novel & $11 \mathrm{C}$ & c. $2941 \mathrm{C}>\mathrm{G}$ & p.Pro981Ala & Missense & 214 & 2 \\
\hline Novel & $11 \mathrm{C}$ & c. $2603 \mathrm{C}>\mathrm{A}$ & p.Ser868* & Nonsense & 480 & 2 \\
\hline Novel & $11 \mathrm{D}$ & c.3363_3367delTACAG & p.Asn1121Lysfs*10 & Frameshift & 1186 & 7 \\
\hline Novel & $11 \mathrm{D}$ & c.3359_3363delTTAAT & p.Val1120Aspfs*11 & Frameshift & 1226 & 5 \\
\hline Novel & 11D & c. $3432 \mathrm{G}>\mathrm{C}$ & p.Gln1144His & Missense & 7 & 3 \\
\hline Novel & $11 \mathrm{D}$ & c.3450delT & p.Asp1151Metfs*4 & Frameshift & 519 & 3 \\
\hline Novel & $11 \mathrm{D}$ & c. $3952 \mathrm{~A}>\mathrm{C}$ & p.Ile1318Leu & Missense & 20 & 2 \\
\hline Novel & $11 \mathrm{D}$ & c.3433delG & p.Val1145Phefs*10 & Frameshift & 7 & 2 \\
\hline Novel & I- 23 & c.5468-1_5474delGCAATTGG & - & IVS & 823 & 8 \\
\hline
\end{tabular}

* The table lists the variants detected in at least two cases in each class 
Table 3: Examples of $B R C A 2$ variants identified in mainland Chinese familial breast and ovarian cancer patients*

\begin{tabular}{|c|c|c|c|c|c|c|}
\hline Class (BIC) & Exon & HGVS annotation & & Variant type & Total cases & Carrier \\
\hline & & cDNA & Protein & & & \\
\hline Class 5 & 3 & c.262_263delCT & p.Leu88Alafs*12 & Frameshift & 518 & 2 \\
\hline Class 5 & 10 & c. $1832 \mathrm{C}>\mathrm{A}$ & p.Ser611* & Nonsense & 518 & 4 \\
\hline Class 5 & 10 & c. $1399 \mathrm{~A}>\mathrm{T}$ & p.Lys467* & Nonsense & 191 & 3 \\
\hline Class 5 & 19 & c. $8485 \mathrm{C}>\mathrm{T}$ & p.Gln2829* & Nonsense & 99 & 2 \\
\hline Class 5 & $11 \mathrm{~B}$ & c.3195_3198delTAAT & p.Asn1066Leufs*10 & Frameshift & 1226 & 5 \\
\hline Class 5 & $11 \mathrm{~B}$ & c.2808_2811delACAA & p.Ala938Profs*21 & Frameshift & 708 & 2 \\
\hline Class 5 & $11 \mathrm{C}$ & c.3744_3747delTGAG & p.Ser1248Argfs*10 & Frameshift & 708 & 2 \\
\hline Class 5 & $11 \mathrm{D}$ & c.5164_5165delAG & p.Ser1722Tyrfs*4 & Frameshift & 518 & 4 \\
\hline Class 5 & $11 \mathrm{E}$ & c.5576_5579delTTAA & p.Ile1859Lysfs*3 & Frameshift & 1302 & 5 \\
\hline Class 5 & $11 \mathrm{E}$ & c. $5682 \mathrm{C}>\mathrm{G}$ & p.Tyr1894* & Nonsense & 99 & 2 \\
\hline Class 5 & $11 \mathrm{~F}$ & c.6591_6592delTG & p.Glu2198Asnfs*4 & Frameshift & 409 & 3 \\
\hline Class 5 & 23 & c.9098_9099insA & p.Gln3034Serfs*10 & Frameshift & 518 & 4 \\
\hline Pending & 10 & c. $865 \mathrm{~A}>\mathrm{C}$ & p.Asn289His & Missense & 321 & 13 \\
\hline Novel & 10 & c.1303dupA & p.Arg435Lysfs*17 & Frameshift & 708 & 2 \\
\hline Novel & 10 & c.1881delA & p.Pro628Hisfs*16 & Frameshift & 708 & 2 \\
\hline Novel & $11 \mathrm{~A}$ & c. 2442 delC & p.Met815Trpfs*10 & Frameshift & 708 & 2 \\
\hline Novel & $11 \mathrm{E}$ & c. $5864 \mathrm{C}>\mathrm{G}$ & p.Ser1955* & Nonsense & 409 & 2 \\
\hline Novel & $11 \mathrm{~F}$ & c.6645_6648CTCC & p.Tyr2215* & \begin{tabular}{|l|} 
Nonsense \\
\end{tabular} & 375 & 3 \\
\hline Novel & $11 \mathrm{~F}$ & c.6150_6151insT & p.Asn2051* & Nonsense & 109 & 2 \\
\hline Novel & 14 & c.7142delC & p.Pro2381Hisfs*13 & Frameshift & 99 & 5 \\
\hline Novel & 18 & c. $8172 \mathrm{delG}$ & p.Trp2725Glyfs*8 & Frameshift & 109 & 3 \\
\hline Novel & 18 & c.8234dupT & p.Thr2746Aspfs*18 & Frameshift & 708 & 2 \\
\hline Novel & 19 & c.8400_8403del4ins5 & p.Phe2801Leufs*10 & Nonsense & 409 & 2 \\
\hline Novel & 20 & c. $8517 \mathrm{C}>\mathrm{A}$ & p.Tyr2839* & \begin{tabular}{|l} 
Nonsense \\
\end{tabular} & 181 & 2 \\
\hline Novel & 22 & c. $8820 \_8823 \mathrm{del}$ & p.Gln2941Leufs*34 & Frameshift & 1013 & 3 \\
\hline Novel & 22 & c.8950delT & p.Ser2984Glnfs*4 & Frameshift & 604 & 2 \\
\hline Novel & 23 & c.9105dup & p.Gln3036Serfs*8 & Frameshift & 109 & 4 \\
\hline Novel & 24 & c.9253delA & p.Thr3085Glnfs*19 & Frameshift & 375 & 3 \\
\hline
\end{tabular}

* The table lists the variants detected in at least two cases in each class

Chinese populations: 18 of 409 (4.4\%) Chinese BRCA1 variant carriers carried this variant, compared with only 18 of $15,311(0.1 \%) B R C A 1$ variant carriers in the BIC database. The most common BRCAl Pending variant was c.3548A $>\mathrm{G}$ (p.Lys1183Arg) in exon 11D $(n=34$; frequency in 1000 Genomes: 0.3526$)$ and c.3113A $>\mathrm{G}$ (p.Glu1038Gly) in exon 11C ( $n=31$, frequency in 1000 Genomes: 0.3357, in Han Chinese Beijing: 0.689). Three Pending variants [c.5470_5477delATTGGGCA (p.Ile1824Aspfs*3), c.5503C $>\mathrm{T} \quad$ (p.Arg1835*)] c.5521delA (p.Ser1841Valfs*2) with high frequencies were located at exon 24, which contributes to the BRCT domain of BRCA1 (Figure 3A). The most common Pathogenic BRCA2 variant was c.3195_3198delTAAT (p.Asn1066Leufs*10) in exon 11B $(n=5)$ and c.5576_5579delTTAA (p.Ile1859Lysfs*3) in exon 11E $(n=5)$, and the most common Pending variant was c. $865 \mathrm{~A}>\mathrm{C}$ (p.Asn289His) in exon $10(n=13$; frequency in 1000 Genomes: 0.0737). Except for the BRCA1 c.981 982delAT variant, other known pathogenic and Pending variants in either $B R C A 1$ or $B R C A 2$ are unlikely to be founder mutation candidates among mainland Chinese patients due to their lower prevalence or higher frequency in normal population.

No variants were found to overlap with other ethnicspecific $B R C A$ founder mutations, including BRCA1 185delAG (c.66_67delAG, HGVS nomenclature) and 5382insC (c.5263_5264insC) and BRCA2 6174delT (c.5946delT) in Ashkenazi Jews [10]; BRCA1 c.4153delA (c.4035delA), C61G (c.-58C >G), and 5382insC (c.5263_5264insC) in Poles [11]; BRCA1 c.303T $>\mathrm{G}$, c.5324T $>\mathrm{G}$, c.1623dupG, and c.4122_4123delTG in Africans [12]; BRCAl ex9-12del in Mexicans [13], and BRCA2 c.7480C $>\mathrm{T}$ in Koreans [14]. 


\section{Novel $B R C A$ variants}

Eighty-one (59.4\%) BRCA1 variants and 46 (57.5\%) $B R C A 2$ variants are not recorded in the BIC database (Figure 4). A total of 19 of these $81 B R C A 1$ variants and 15 of the $46 B R C A 2$ variants were detected in at least two cases, with c.919A $>\mathrm{G}$ (p.Lys307Glu) in BRCA1 exon 11A $(n=10)$, c.7142delC (p.Pro2381Hisfs*13) in BRCA2 exon $14(n=5)$ having the highest frequencies. We compared these novel variants with the $B R C A$ variant dataset from Asian populations [60], and identified 35 overlapping variants (18 in BRCA1 and 17 in $B R C A 2$ ). Thirty-three $(94.3 \%)$ of these overlapping variants were from Chinese ethnicity but not from other ethnicities (Supplementary Table 6), confirming that these novel variants are mainland Chinese-specific. The presence of multiple novel variants provides a rich resource to identify new $B R C A$ pathogenic mutations in mainland Chinese population.

In conclusion, our study indicates that $B R C A$ variations are common in mainland Chinese familial breast and ovarian cancer patients. The absence of such information in current international BRCA databases appears to largely reflect the poor communication between Western and Chinese scientific communities. Our study also indicates while the prevalence of $B R C A$ variation is similar to that of other populations, the spectrum of $B R C A$ variation in Chinese patients differs substantially with the hot spots of BRCA1 exons $11 \mathrm{~A}, 11 \mathrm{C}, 11 \mathrm{D}, 24$ and $B R C A 2$ exon 10. Except the c.981_982delAT in BRCA1 exon $11 \mathrm{~A}$, there is no strong evidence showing the presence of common founder BRCA mutations in mainland Chinese patients, although such a possibility may exist in certain subpopulations of specific geographic regions or ethnic groups in mainland China.

\section{MATERIALS AND METHODS}

\section{Information sources}

We searched two major Chinese scientific databases, China National Knowledge Infrastructure (CNKI) [63] and WanFang [16], which comprehensively collect information from Chinese academic journals, dissertations, conference proceedings, and patents, by using the key words "breast cancer", "BRCA1 mutation", and "BRCA2 mutation" in Chinese characters. From the identified publications, we excluded those of sporadic breast cancer, animals, and those about patients marked with "early diagnosis", "triple-negative", and "bilateral" but without age indication, "male", and from non-mainland Chinese. Using similar approaches but in English, we also searched the PubMed database to identify non-Chinese publications reporting $B R C A$ mutations from mainland Chinese patients (Figure 1).
We applied multiple steps to ensure the reliability of the identified variants, including: 1) only including variants detected or validated by Sanger sequencing; 2 ) re-annotating all variants following HGVS nomenclature using the reference sequences U14680 for $B R C A 1$ and U43746 for $B R C A 2$, regardless of original annotation; 3 ) using the BIC database (13-Mar-2015 version) as a reference to classify variants as known variants with BIC designation or novel variants without BIC designation; 4) excluding synonymous variants and un-interpretable variants from analysis; and 5) annotating novel variants by referring to their effects on coding changes in BRCAl and $B R C A 2$. We used U14680 and U43746 as the reference sequences for BRCA1 and BRCA2 annotation, as they were used as the standard references by most of the cited publications and BIC database. However, different $B R C A$ databases may use different $B R C A$ reference sequences, which can generate differences for certain variants. For example, Clinvar database uses NM_007294 and NM 000059 as the references for BRCA1 and $B R C A 2$ (64). To facilitate data comparison with $B R C A$ variants annotated by Clinvar database, we also included the variants annotated by using these two references (Supplementary Tables 3,4). All variants were annotated following HGVS nomenclature.

\section{Abbreviations}

BIC: Breast Cancer Information Core; BRCA1: breast cancer 1, early onset; BRCA2: breast cancer 2, early onset; HGVS: human genome variation society.

\section{GRANT SUPPORT}

The study was supported by an NIH grant CA180008 (SMW), an American Cancer Society Institutional Research Grant (YK), and Chinese Scholar Council fellowships (LZ, JC and FX).

\section{CONFLICTS OF INTEREST}

The authors declare no competing interests.

\section{REFERENCES}

1. Pavlicek A, Noskov VN, Kouprina N, Barrett JC, Jurka J, Larionov V. Evolution of the tumor suppressor BRCA1 locus in primates: implications for cancer predisposition. Hum Mol Genet. 2004; 13:2737-2751.

2. Jin H, Selfe J, Whitehouse C, Morris JR, Solomon E, Roberts RG. Structural evolution of the BRCA1 genomic region in primates. Genomics. 2004; 84:1071-1082.

3. Lou DI, McBee RM, Le UQ, Stone AC, Wilkerson GK, Demogines AM, Sawyer SL. Rapid evolution of BRCA1 and BRCA2 in humans and other primates. BMC Evol Biol. 
$2014 ; 14: 155$.

4. Hall JM, Lee MK, Newman B, Morrow JE, Anderson LA, Huey B, King MC. Linkage of early-onset familial breast cancer to chromosome 17q21. Science. 1990; 250:16841689.

5. Miki Y, Swensen J, Shattuck-Eidens D, Futreal PA, Harshman K, Tavtigian S, Liu Q, Cochran C, Bennett LM, Ding W, Bell R, Rosenthal J, Hussey C et al. A strong candidate for the breast and ovarian cancer susceptibility gene BRCA1. Science. 1994; 266:66-71.

6. Welcsh PL, King MC. BRCA1 and BRCA2 and the genetics of breast and ovarian cancer. Hum Mol Genet. 2001;10:705-713.

7. Stratton MR, Rahman N. The emerging landscape of breast cancer susceptibility. Nat Genet. 2008; 40:17-22.

8. Couch FJ, Nathanson KL, Offit K. Two decades after BRCA: setting paradigms in personalized cancer care and prevention. Science. 2014; 343:1466-1470.

9. Janavičius R. Founder BRCA1/2 mutations in the Europe: implications for hereditary breast-ovarian cancer prevention and control. EPMA J. 2010; 1:397-412.

10. Struewing JP, Hartge P, Wacholder S, Baker SM, Berlin M, McAdams M, Timmerman MM, Brody LC, Tucker MA. The risk of cancer associated with specific mutations of BRCA1 and BRCA2 among Ashkenazi Jews. N Engl J Med. 1997; 336:1401-1408.

11. Górski B, Jakubowska A, Huzarski T, Byrski T, Gronwald J, Grzybowska E, Mackiewicz A, Stawicka M, Bebenek M, Sorokin D, Fiszer-Maliszewska $Ł$, Haus O, Janiszewska H et al. A high proportion of founder BRCA1 mutations in Polish breast cancer families. Int J Cancer. 2004; 110:683686.

12. Zhang J, Fackenthal JD, Zheng Y, Huo D, Hou N, Niu Q, Zvosec C, Ogundiran TO, Hennis AJ, Leske MC, Nemesure B, Wu SY, Olopade OI. Recurrent BRCA1 and BRCA2 mutations in breast cancer patients of African ancestry. Breast Cancer Research and Treatment. 2012; 134: 889894.

13. Villarreal-Garza C, Alvarez-Gómez RM, Pérez-Plasencia C, Herrera LA, Herzog J, Castillo D, Mohar A, Castro C, Gallardo LN, Gallardo D, Santibáñez M, Blazer KR, Weitzel JN. Significant clinical impact of recurrent BRCA1 and BRCA2 mutations in Mexico. Cancer. 2015; 121:372378.

14. Kang E, Seong MW, Park SK, Lee JW, Lee J, Kim LS, Lee JE, Kim SY, Jeong J, Han SA, Kim SW; Korean Hereditary Breast Cancer Study Group. The prevalence and spectrum of BRCA1 and BRCA2 mutations in Korean population: recent update of the Korean Hereditary Breast Cancer (KOHBRA) study. Breast Cancer Res Treat. 2015; 151:157-168.

15. https://research.nhgri.nih.gov/projects/bic/, Accessed August 26, 2015

16. http://www.wanfangdata.com/COJ/intr.asp\#China Online
Journals (COJ) in Health/Medicine/Biology, Accessed July 10,2015

17. Deng SM, Wang $\mathrm{Y}, \mathrm{Ke} \mathrm{Y}, \mathrm{Xu}$ GW. Analysis of the mutations of BRCA1 in 9 familial breast cancer patients. Journal of Peking University (Health Sciences). 2003; 35:373-376.

18. Li N, Zhang X, Cai Y, Xu X, Zhang L, Pan KF, Wu LY, Wang MR. BRCA1 germline mutations in Chinese patients with hereditary breast and ovarian cancer. Int J Gynecol Cancer. 2006; 16:172-178.

19. Zhen LL, Wu ZY, Fan P, Wang S, Liu X, Wang XY. Analysis of breast cancer susceptibility gene-1 mutations in Chinese familial breast cancer patients. Chin J Exp Surg. 2003; 20: 170-171.

20. Hu Z, Wu J, Liu CH, Lu JS, Luo JM, Han QX, Shen ZZ, Shao ZM. The analysis of BRCA1 mutations in eastern Chinese patients with early onset breast cancer and affected relatives. Human Mutation. 2003; 22:104.

21. Zhou YZ, Sun Q, Lin SQ, Wang J, Liu B, Li JX, Zhou YD, Ye J, Han H, Fang FD. Germline mutations in the BRCA1 and BRCA2 genes from breast cancer families in China Han people [Article in Chinese]. Zhonghua Yi Xue Za Zhi. 2004; 84:294-298.

22. Suter NM, Ray RM, Hu YW, Lin MG, Porter P, Gao DL, Zaucha RE, Iwasaki LM, Sabacan LP, Langlois MC, Thomas DB, Ostrander EA. BRCA1 and BRCA2 Mutations in women from Shanghai China. Cancer Epidemiology. 2004; 13:181-189.

23. Song CG, Hu Z, Yuan WT, Di GH, Shen ZZ, Huang W, Shao ZM. Mutational analysis of BRCA1 and BRCA2 genes in early-onset breast cancer patients in Shanghai [Article in Chinese]. Zhonghua Yi Xue Za Zhi. 2005; 85:3030-3034.

24. Wu YH. Screen BRCA1 variations in 76 Chinese familial breast cancer patients and analyze the relationship between mutations and pathologic features. 2005; 1-92. (http:// d.g.wanfangdata.com.cn/Thesis_Y761953.aspx).

25. Song CG, Hu Z, Yuan WT, Di GH, Shen ZZ, Huang W, Shao ZM. BRCA1 and BRCA2 gene mutations of familial breast cancer from Shanghai in China [Article in Chinese]. Zhonghua Yi Xue Yi Chuan Xue Za Zhi. 2006; 23:27-31.

26. Song CG, Hu Z, Wu J, Luo JM, Shen ZZ, Huang W, Shao ZM. The prevalence of BRCA1 and BRCA2 mutations in eastern Chinese women with breast cancer. J Cancer Res Clin Oncol. 2006; 132:617-626.

27. Chen LF, Geng CZ, Wang GL, Li JG. BRCA1/2 gene mutations of familial and sporadic breast cancer from Hebei Province in China. Chin J Breast Dis. 2010; 4:418-426.

28. Hu Z, Li WF, Liu XY, Zhang B, Cao MZ, Wang YS, Zhao L, Song CG, Lu JS, Wu J, Di GH, Shen KW, Han QX, Shen ZZ, Huang W, Shao ZM. 5589del8: the recurrent mutation of BRCA1 gene in Chinese breast cancer patients [Article in Chinese]. Zhonghua Yi Xue Yi Chuan Xue Za Zhi. 2007; 24:378-381. 
29. Li WF, Hu Z, Liu XY, Zhang B, Cao MZ, Wang YS, Zhao L, Liu YB, Yuan WT, Shen ZZ, Huang W, Shao ZM. BRCA1 germ line mutation in Chinese early-onset breast cancer patients [Article in Chinese]. Zhonghua Yi Xue Yi Chuan Xue Za Zhi. 2007; 24:499-504.

30. Li WF, Hu Z, Zhang B, Cao MZ, Wang YS, Liu XY, Zhao L, Liu YB, Yuan WT, Shen ZZ, Huang W, Shao ZM. BRCA1 1100delAT is a recurrent mutation in Chinese women with familial breast cancer [Article in Chinese]. Zhonghua Yi Xue Za Zhi. 2007; 87:76-80.

31. Li WF. The prevalence of BRCA1 and BRCA2 germline mutations in high-risk breast cancer patients of Chinese Han nationality. 2007; 1-106. DOI:10.7666/d.y1171324.

32. Zhou J, Rao NY, Li SR, Jin L, Jia WJ, Gong C, Yu FY, Su FX, Song EW, Shao ZM. Analysis of BRCA1 gene mutations in patients with early-onset breast cancer and their affected relatives in Guangdong province [Article in Chinese]. Nan Fang Yi Ke Da Xue Xue Bao. 2009; 29:213216.

33. Hu Z, Li WF, Liu XY, Zhang B, Cao MZ, Wang YS, Zhao L, Song CG, Lu JS, Wu J, DI GH, Shen KW, Han QX, Shen ZZ, Huang W, Shao ZM. BRCA1/2 gene mutation in Chinese familial breast cancer patients: a multi-center report of 115 cases [Article in Chinese]. Zhonghua Yi Xue Za Zhi. 2008; 88:2383-2386..

34. Li WF, Hu Z, Rao NY, Song CG, Zhang B, Cao MZ, Su FX, Wang YS, He PQ, Di GH, Shen KW, Wu J, Lu JS et al. The Prevalence of BRCA1 and BRCA2 germline mutations in high-risk breast cancer patients of Chinese Han nationality: two recurrent mutations were identified. Breast Cancer Res Treat. 2008; 110:99-109.

35. Ma ZL. The analysis of BRCA1/2 mutations among familial and/or early-onset breast cancer patients in eastern Shandong of China. 2008; 1-49. DOI:10.7666/d.y1335403.

36. Rao NY, Zhou J, Zhao L, Hu Z, Di GH, Su FX, Li WF, Shen ZZ, Shao ZM. BRCA1 and BRCA2 deleterious mutation in 219 Han hereditary breast cancer patients. China Oncology. 2008; 18:370-375.

37. Cao MZ, Ma ZL, Liu XY, Kong B, Li WF, Shao ZM. Analysis of BRCA1 mutations among familial and/ or breast cancer praecox patients in the east of Shandong in China. Progress in Modern Biomedicine. 2009; 9:10281030.

38. Chen W, Pan K, Ouyang T, Li J, Wang T, Fan Z, Fan T, Lin B, Lu Y, You W, Xie Y. BRCA1 germline mutations and tumor characteristics in Chinese women with familial or early-onset breast cancer. Breast Cancer Res Treat. 2008; 117:55-60.

39. Huang J, Tang LL, Hu Z, Xia T, Rao NY, Shao ZM. BRCA1 and BRCA2 gene mutations of familial breast cancer and early-onset breast cancer from Hunan province in China. China Oncology. 2008; 18:566-572.

40. Jiang Y, Wang WB, Guo QW, Ge YS, Zhou YL. BRCA1 gene mutations of the hereditary breast cancer from Fujian in China. Chinese Journal of Birth Health and Heredity. 2009; 17: 20-22.

41. Meng J, Shi YR, Niu RF, Fu L. Relationship between mutation of BRCA1 and susceptibility to early onset of breast cancer. Natl Med J China. 2009; 89:79-82.

42. Zhang L. BRCA1 gene exon2 and exon 20 mutation detection of familial breast cancer and early-onset breast cancer from Qingdao in China. 2009; 1-39. DOI:10.7666/d. y1469508.

43. Xue WN, Wang JS, Song YN, He C, Zhang YX, Pang D. BRCA1 gene mutations analysis of familial breast cancer and early-onset breast cancer. Journal of Practical Oncology. 2010; 24:408-412.

44. Kong LL, Cui W, Wang X, Jiang XG, Zhang GA. Analysis of the mutations of BRCA1 in familial breast cancer patients. J Jining Med Univ. 2011; 34: 96-97.

45. Li JG, Hui TL, Li Z, Bai Y, Ma GM, Sun YQ, Li CX, Geng CZ. BRCA1 and BRCA2 gene mutations in familial breast cancer. Chin J Breast Dis. 2012; 6: 631-639.

46. Li Z. Analysis of BRCA1 and BRCA2 mutations among familial breast cancer patients in Hebei province of China. 2009; 1-57. DOI:10.7666/d.y2105804.

47. Yin LL, Chen YP, Yang BZ, Wu RF, Kang YZ. BRCA1/ BRCA2 gene mutation analysis in Hui familial breast cancer patients. Modern Immunity. 2012; 32:115-118.

48. Zhang WX, Wang EL, Xie JS, Zhong CE, Zhou J, Liu JL, Chen SJ. The comparison of BRCA1 gene mutation between familial and sporadic breast cancer patients. Chin J Clinicians. 2012; 6:5305-5308.

49. Zhang J, Pei R, Pang Z, Ouyang T, Li J, Wang T, Fan Z, Fan T, Lin B, Xie Y. Prevalence and characterization of BRCA1 and BRCA2 germline mutations in Chinese women with familial breast cancer. Breast Cancer Res Treat. 2012; 132:421-428.

50. Ni SS. Study on risk factors and BRCA1/2 germline mutations of breast cancer in Zhejiang province. 2012; 1-75 (http://d.g.wanfangdata.com.cn/Thesis_Y2119858.aspx).

51. Cao WM. Study on BRCA1/BRCA2 germline mutation in Chinese women with high-risk breast cancer. 2013; 1-110 (http://d.g.wanfangdata.com.cn/Thesis_Y2385781.aspx).

52. Wu T, Wang XM, Ou JH, Zhu LP, Xu WT, Chen L, Ni D. BRCA mutations and clinical pathological features of 30 patients with high-risk triple negative breast cancer in Xinjiang Uygur autonomous region. Cancer Research and Clinic. 2013; 25:738-741.

53. Ou JH, Wu T, Sijmons R, Ni D, Xu WT, Upur H. Prevalence of BRCA1 and BRCA2 germline mutations in breast cancer women of multiple ethnic region in northwest China. J Breast Cancer. 2013; 16:50-54.

54. Li YT. Research of breast cancer susceptibility gene BRCA1/2, BRIP1, PALB2, CHEK2 in the genetic background of the patients with breast cancer in Xinjiang. 2014;1-122. (http://www.cnki.net/KCMS/detail/1.x?QueryI $\underline{\mathrm{D}=0 \& \text { CurRec }=1 \& \text { recid }=\text { \&filename }=1015544614 \text {.h\&dbnam }}$ 


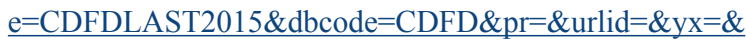
v=MTUxNDFYMUx1eFITN0RoMVQzcVRyV00xRnJDVtRkN2blc3ckJWRjI2RzdhOEd0Zk5xNUViUEISOGU=).

55. Li YT, Ni D, Yang L, Zhao Q, Ou JH. The prevalence of BRCA1/2 mutations of triple-negative breast cancer patients in Xinjiang multiple ethnic region of China. Eur $\mathrm{J}$ Med Res. 2014; 19:35-39.

56. Wu X, Chen JM, Di W. The detection of BRCA1/2 gene mutations of recurrent uterine serous carcinoma patients with hereditary breast and ovarian cancer syndrome background by the second generation sequencing technology. Chinese journal of obstetrics and gynecology. 2014; 49:647-649.

57. Xu WT, Yi LN, Ou JH, Wu T. 82 cases of high-risk breast cancer patients with BRCA1/2 genetic mutation research in Xinjiang region. Medical Information. 2015; 21:85-86.

58. Wang C, Zhang J, Wang Y, Ouyang T, Li J, Wang T, Fan Z, Fan T, Lin B, Xie Y. Prevalence of BRCA1 mutations and responses to neoadjuvant chemotherapy among BRCA1 carriers and non-carriers with triple-negative breast cancer. Ann Oncol. 2015; 26:523-528.

59. Yang X, Wu J, Lu J, Liu G, Di G, Chen C, Hou Y, Sun M, Yang W, Xu X, Zhao Y, Hu X, Li D et al. Identification of a comprehensive spectrum of genetic factors for hereditary breast cancer in a Chinese population by next-generation sequencing. PLoS One. 2015; 10:e0125571.

60. Kwong A, Shin VY, Ho JC, Kang E, Nakamura S, Teo SH, Lee AS, Sng JH, Ginsburg OM, Kurian AW, Weitzel JN, Siu MT, Law FB. Comprehensive spectrum of BRCA1 and BRCA2 deleterious mutations in breast cancer in Asian countries. J Med Genet. 2015; pii: jmedgenet-2015-103132. doi: 10.1136/jmedgenet-2015-103132.

61. https://research.nhgri.nih.gov/projects/bic/Member/cgibin/ bic_full_summary.cgi?table=brcal_exons

62. https://research.nhgri.nih.gov/projects/bic/Member/cgibin/ bic full_summary.cgi?table=brca2 exons

63. http://oversea.cnki.net/kns55/default.aspx. Accessed July $10,2015$.

64. http://www.ncbi.nlm.nih.gov/clinvar/, Accessed January 10, 2016. 